\title{
Some cytological and ultrastructural aspects of male sterility in Impatiens
}

J. L. VAN WENT

Department of Plant Cytology and Morphology, Agricultural University, Arboretumlaan 4, Wageningen, The Netherlands

Abstract

Some cytological and ultrastructural aspects of tapetum and sporogenic cells, in both male-fertile and male-sterile Impatiens, were investigated and compared in order to find the cause of cytoplasmic male sterility.

\section{INTRODUCTION}

Cytoplasmic male sterility (CMS) has been reported in a lange number of species (L a s er, Lersten, 1972). It is now widely used by plant breeders for mass production of hybrid seeds, although little is known about its exact nature or mechanism. CMS can result from malfunctioning of almost any or every stage of microsporogenesis and pollen development.

Investigators have frequently observed abnormal development of the anther tapetum, ranging from its premature degeneration to profuse proliferation, in relation to the degeneration of the microspore mother cells (MMC), microspores (MS) or pollen (O v e r m a n, W a r m k e, 1972; $\mathrm{N}$ anda, Gupta, 1974; Horner, 1977; Le e et al., 1979). The abnormal development of the tapetum is usually interpreted as malfunctioning, and regarded as the direct or indirect cause of CMS.

In the present study some cytological and ultrastructural aspects of tapetum and sporogenic cells, in both male-fertile and male-sterile Impatiens, were investigated and compared in order to find the cause of CMS. Besides, the knowledge of abnormal ontogeny can be of help for a better understanding of normal microsporogenesis and pollen formation.

\section{MATERIAL AND METHODS}

Genetically close male-sterile, and normal lines of Impatiens walleriana Hook. f. were used in this investigation. Dissected anthers were fixed in $2.5 \%$ glutaraldehyde in $0.1 \mathrm{M}$ sodium-cacodylate buffer $(\mathrm{pH} 7.0)$ 
for $2 \mathrm{hr}$ and subsequently postifixed in $1 \% \mathrm{OsO}_{4}$ in the same buffer for $15 \mathrm{hr}$. During dehydration the material was stained with $2 \%$ uranyl acetate in $70 \%$ ethanol for $30 \mathrm{~min}$. Thin sections were poststained with lead citrate.

\section{RESULTS AND DISCUSSION}

The organization of the anther, and the cytological and ultrastructural development of the MMC and tapetal cells in male-fertile and malesterile anthers are identical up to the tetrad stage. The tapetal cells are arranged in rows and layers which surround and transverse the locule, separating numerous small groups of MMC. At the late premeiotic and early phophase stages the tapetal cells can be recognized by their small size, presence of vacuoles, and small nuclei with regularly spread chromatin and small nucleoli. The MMC are completely filled with cytoplasm and have large nuclei, each with a large nucleolus. At these young stages both MMC and tapetal cells show similar cytoplasmic ultrastructure. During the meiotic prophase both MMC and tapetal cells enlarge and develop a specific ultrastructure. In the MMC there is an appreciable increase of mitochondria and dictyosomes; a lesser increase of plastids and formation of starch grains, whereas the number of ribosomes remains constant. In the tapetal cells an extensive RER is formed, the ribosomes increase, whereas the mitochondria, dictyosomes and plastids do not change much in number. During their development some tapetal cells become binucleate and their walls dissolve.

Differences between male-fertile and male-sterile anthers become apparent at the time of release of microspores from the tetrads. In the former the callose dissolves quickly and completely, the microspores enlarge slowly but the tapetal cells continue to have the same dimension and composition (Fig. 1). In the latter the dissolution of the callose is relatively slow, its remnants can be observed long after the microspores have been released; some microspores show local swelling and subsequently begin to shrink, but the tapetal cells enlarge and become vacuolated (Fig. 2).

In the fertile anther, the initial low growth of the microspores is followed by their considerable enlargement, which is accompanied by prominent vacuolation, whereas the amount of cytoplasm and the number of organelles do not change (Fig. 3). During vacuolation mitosis takes place, and the ultrastructure of the tapetal cells changes. The amount of ER greatly increases, mitochondria become grouped together forming complex organized aggregates, and the number of plastids, dictyosomes and ribosomes gradually decreases. Ultimately the tapetal cells degenerate, while the microspores are still at the vacuolate stage. 

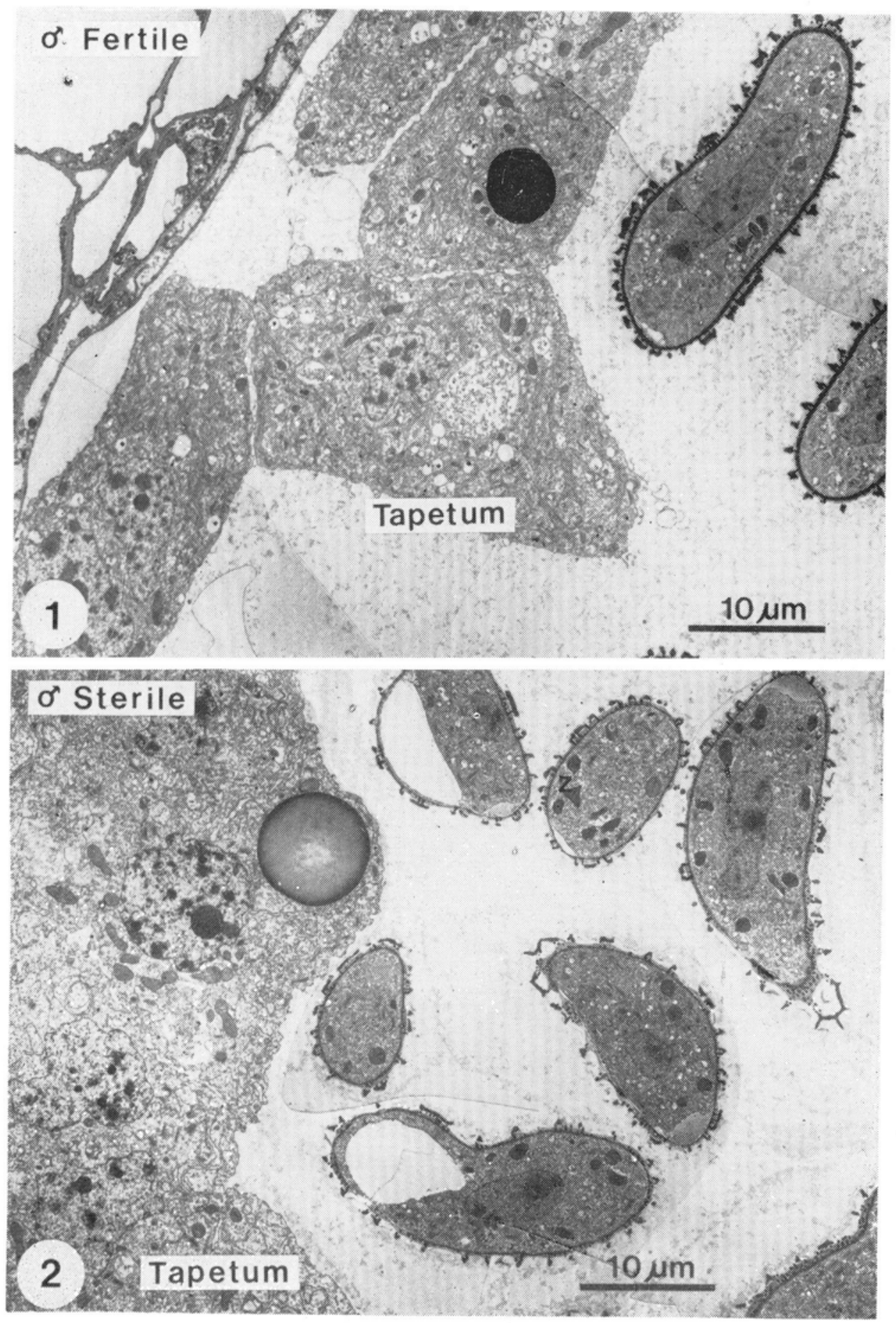

Fig. 1 Microspores and tapetum cells of fertile anther, just before vacuolation and mitosis of spores. Tapetum cells have lost their walls and some of them are binucleate. $\times 2.000$

Fig. 2. Microspores and tapetum cells of sterile anther, at the onset of vacuolation and mitosis of spores. Exine formation is delayed and tapetum cells are prolife- 

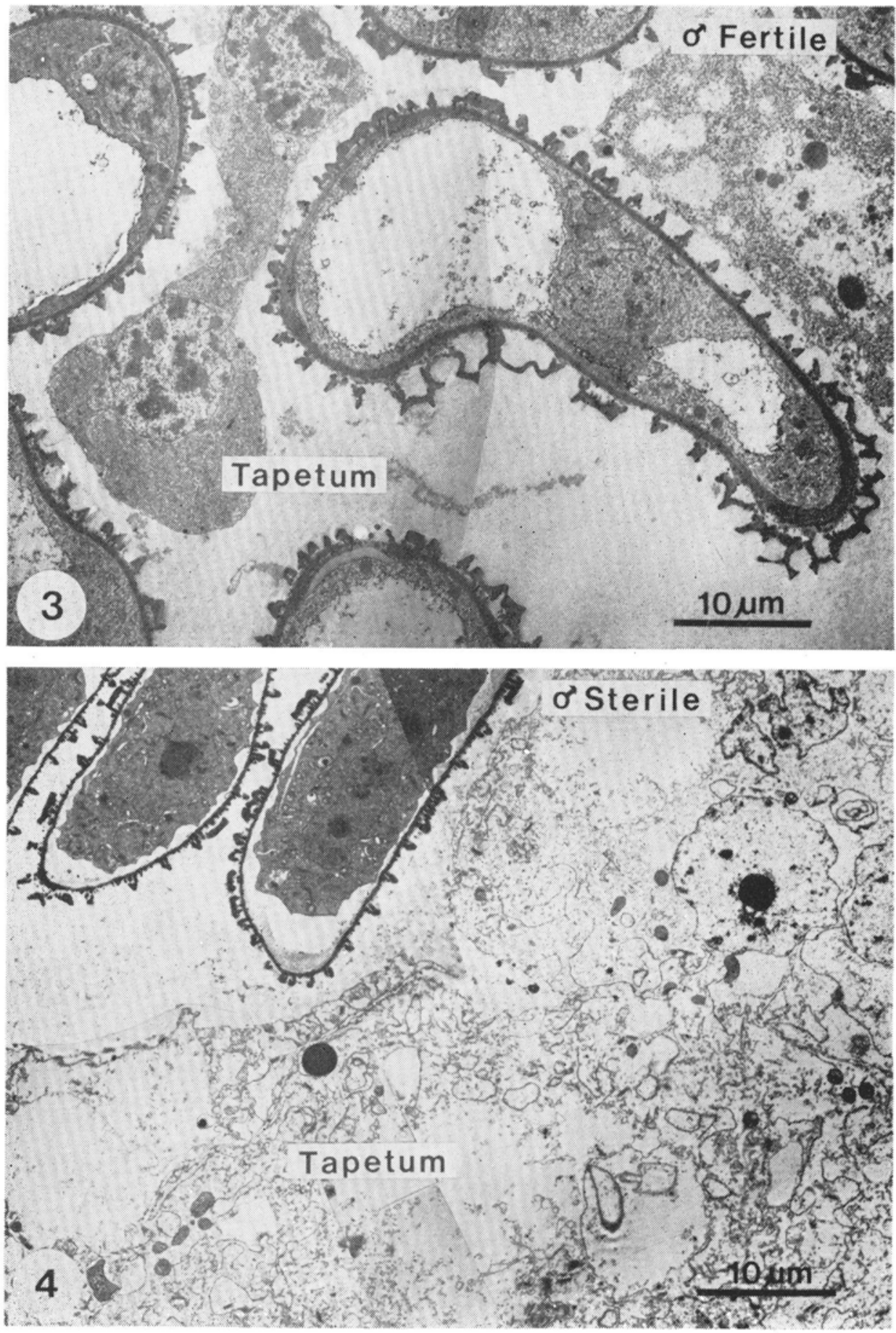

Fig. 3. Vacuolated pollen after formation of generative cell in fertile anther. Degeneration of tapetum cells is starting. $\times 2.000$

Fig. 4. Plasmolysis of microspores in sterile anther. After initiation, both vacuolation and mitosis become arrested in the microspores. Tapetum cells show strong 

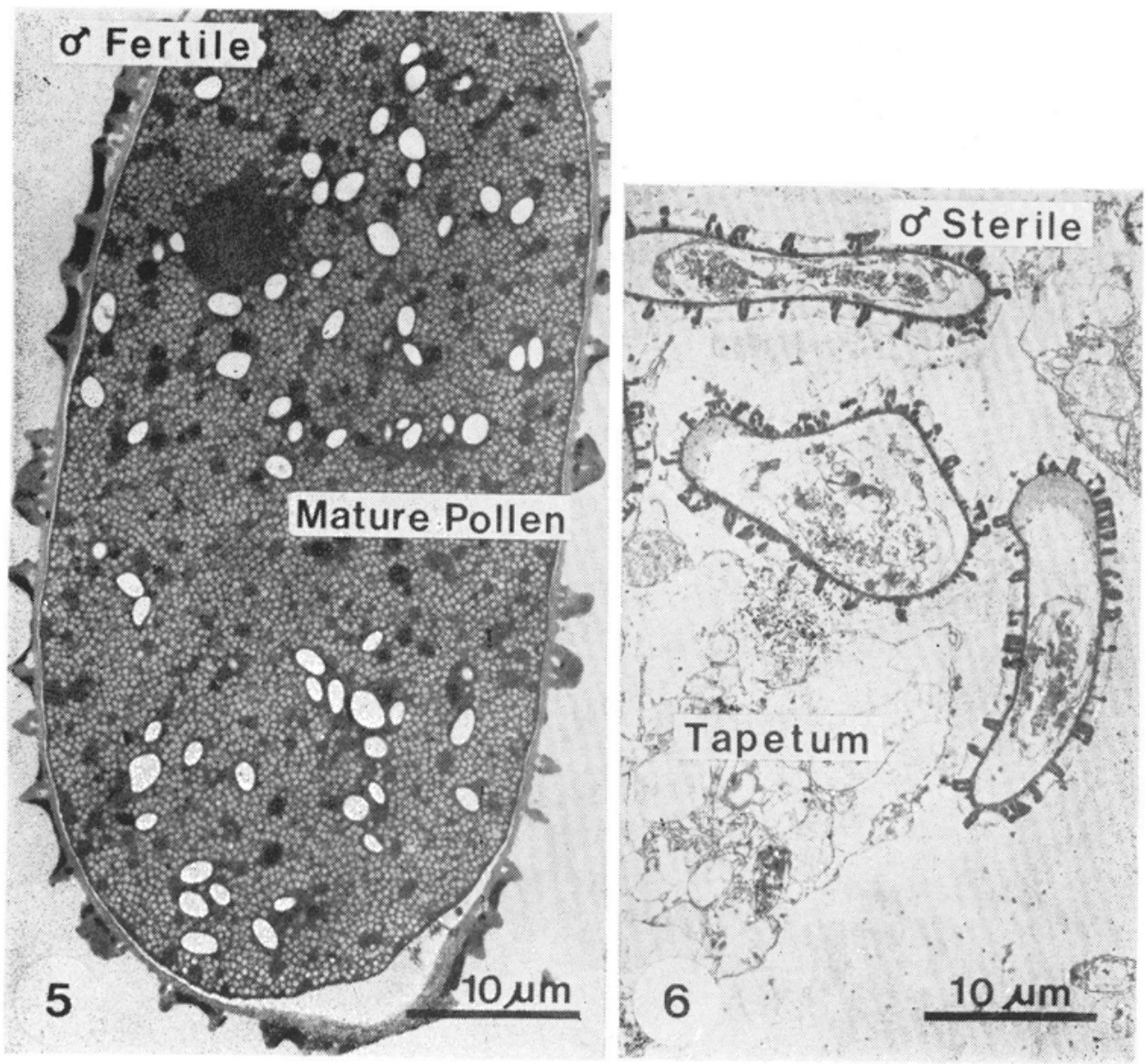

Fig. 5. Mature pollen grain from fertile anther. $\times 2.000$

Fig. 6. Degeneration of both microspores and tapetum cells in the sterile anther. $\times 2.000$ 
In the sterile anther, the microspores as well as the tapetal cells show completely different ultrastructural development (Fig. 4). In the microspores vacuolation is initiated to some extent, but enlargement of the vacuoles only leads to their local bulging and soon the vacuoles collapse. As a result the microspores do not enlarge. Mitosis too is initiated, but is arrested at prophase. The enlargement of the tapetal cells is accompanied by both vacuolation and increase of cytoplasm, but the number of organelles does not change. As the cytoplasmic volume increases and the organelles are evenly distributed, the cytoplasm appears diluted. In the tapetal cells, most organelles keep their original ultrastructure, except that the mitochondria become wrinkled. Subsequently the cells fuse, or their membranes are disrupted, forming massive plasma. Simultaneously numerous nuclei are formed. At this stage the microspores are still intact, but appear highly plasmolyzed. Development ultimately ends with the desintegration and break-down of the entire locular content (Fig. 6).

The foregoing results demonstrate that in Impatiens abnormal development in the sterile anther starts at the time of release of microspores from the tetrads. It is marked by a slight delay in callose dissolution. Soon after, the tapetal cells begin to enlarge and become vacuolated but fail to develop the specific ultrastructure of the fertile anther tapetum and the cytoplasm becomes highly diluted. In microspores the processes of exine formation, mitosis and vacuolation are initiated, but become arrested, and the cells do not enlarge. They, however, remain alive as is evident from their ultrastructure, and also from the fact that the membrane still shows permeability activity as the cells are plasmolysed, until the entire locular content simultaneously dissolves.

It is unlikely that the initial callose disturbance alone is responsible for abnormal development in the sterile abnormal development in the sterile anther, since there is only a minor delay in its dissolution. This, however, indicates an aberrant cell metabolism at this time. Since enlargement and vacuolation of tapetal cells and microspores are reverse in the sterile anther, it appears that the molar conditions of locular fluid, tapetal cells and microspores play an important role. Preliminary studies show that the microspores of the sterile anther normally swell and enlarge when they are isolated from the anther and placed in water. This means that the abnormal tapetal cells have an extremely high osmolarity, since they prominently enlarge whereas the microspores plasmolyse. It is, therefore, presumed that microspore development in the sterile anther is merely blocked as a result of malfunctioning of the abnormal tapetum, resulting in male sterility. 


\section{REFERENCES}

Horner H. T., 1977. A Comparative light- and electron-microscopical study of microsporogenesis in male-fertile and cytoplasmic male-sterile sunflower (Helianthus annuus). Amer. J. Bot. 64: 745-759.

Laser K. D., Lersten N. R., 1972. Anatomy and cytology of microsporogenesis in cytoplasmic male sterile angiosperms. Bot. Rev. 38: 425-454.

Lee S. J., Gracen V. E., Earle E. D., 1979. The cytology of pollen abortion in C-cytoplasmic male-sterile corn anthers. Amer J. Bot. 66: 656-667.

Nanda K. D., Gupta S. C., 1974. Malfunctioning tapetum and callose wall behaviour in Allium cepa microsporangia. Beitr. Biol. Pflanzen 50: 465-472.

Overman M. A., W armke H. E., 1972. Cytoplasmic male sterility in Sorghum II Tapetal behaviour in fertile and sterile anthers. J. Hered. 63: 227-234. 